\title{
Aggressive Periodontitis and a Prosthetic Solution: 7-Month Follow-Up
}

\author{
Raisa Queiroz Catunda*1, Bruno Gustavo da Silva Casado ${ }^{2}$ and Renato Vasconcelos Alves ${ }^{3}$,Jordana de \\ Oliveira Silva ${ }^{4}$
}

${ }^{1} \mathrm{PhD}$ student, Faculty of Medicine and Dentistry, University of Alberta, Canada

${ }^{2}$ PhDstudent, Faculty of Dentistry, University of Pernambuco, Brazil

${ }^{3}$ Professor, Faculty of Dentistry, University of Pernambuco, Brazil

${ }^{4}$ Periodontist, Associação Brasileira de Odontologia - Seção Pernambuco, Brazil

Received: May 22, 2018; Published: May 29, 2018

*Corresponding author: Raisa Queiroz Catunda, Faculty of Medicine and Dentistry, Katz 7020-11361-87 ${ }^{\text {th }}$ Avenue NW, Edmonton, Alberta, Canada T6G 2E1

\section{Abstract}

The terms gingival prosthesis, gingival epithesis or gum mask are used to describe the replacement of lost gingival tissue with a removable prosthesis. This case report aimed to clarify the indications, contraindications, advantages and disadvantages of making a gum epithesis in a 21-year-old female patient with aggressive periodontitis, who attended Clínica de Especializaçãoem Periodontology Clinic from the Associação Brasileira de Odontologia-Pernambuco Section with losses of interdental papillae on the anterior superior and aesthetic complaint about "dark spaces". The patient underwent basic periodontal treatment consisting of scaling and root planning and oral hygiene orientation, aiming the stability of periodontal inflammation. However, the loss of anterior gingiva was still noticeable. Looking for a functional and aesthetic solution for this problem, gingival epithesis or removable artificial gingiva in acrylic resin was suggested to complement the treatment. The steps of impression, wax try-in and manufacture of gum epithesis in acrylic resin were made. After adjustments, the prosthesis was adapted to the patient, the guidelines for conservation and cleaning were done and thus a solution to the aesthetic, functional and phonetic filling was achieved for the main complaint of the patient. A follow-up of seven months was performed, no further adjusts were needed and the prosthesis showed appropriate adaptation. Periodontal condition was also assessed and patient was periodontally stable.

Keywords: Epithesis; Aggressive Periodontitis; Periodontal Health; Gingival Esthetic Rehabilitation

\section{Introduction}

The shape of the interdental gingiva (interdental papilla) is determined by the relationships between the teeth, the width of the proximal surface and the contact of the cement-enamel junction [1]. The gingival papilla must fully occupy the space limited by the contact area of the teeth and the interdental bone crest. Both hyperplasia and papilla retraction, consequences of periodontal disease, dramatically alter the aesthetics of the smile [2]. There are many periodontal disorders that can cause inflammation, gingival recession and bone loss. Aggressive periodontitis is one of them. This disease is characterized by an early onset and by its aggressiveness. It occurs in individuals that are less than 30 years of age and has a very rapid progression, without a correspondent amount of plaque or calculus [3]. Advanced cases, most of the time, can result in destruction of the supporting structures of the teeth, promoting the loss of papillae and root exposures. In addition, one of the problems associated with the elimination of periodontal pockets is the long clinical crown [4]. The treatment is generally focused on reestab lishing the periodontal health, early diagnosis, oral hygiene education, systemic antibiotics, a very close follow-up and in some cases, periodontal surgery [5]. Usually, apart from the preoccupation with their oral health, these patients seek the practice looking for an aesthetic solution $[4,6]$.

Some of the solutions to reconstruct interdental papilla are techniques combining the basic principles of the Abram roller technique for augmentation and the Evian papilla preservation technique [7], technique with gingival graft [8], technique using a semi lunar incision [9], technique using buccal and palatine flap with connective tissue graft [10] and root recoating technique associated with interdental papilla reconstruction [11]. Periodontal regeneration may be predictable, when the correct indication is made (deep intra-bony defects) [12]. However, some patients might have systemic disorders that will not allow them to be exposed to a surgical procedure. The epithesis has been indicated to solve problems arising from the use of fixed prostheses and periodontitis, such as 
with high smile lines, poor lip support, bad phonetics and frequent food impaction complaints [13]. Other reasons that might make the patient choose an epithesis over a surgical procedure are the costs (reasonably cheaper), time (fast procedure), predictability and reversibility [14]. Therefore, the aim of this paper is to report a case of a young aggressive periodontitis patient who was rehabilitated functionally and aesthetically using a gingival epithesis.

\section{Case report}

A female patient, leukoderma, 21 years of age, presented at the periodontal clinic of the AssociaçãoBrasileira de Odontologia(Recife-Pernambuco-Brazil) with loss of interdental papillae in the upper anterior region and aesthetic complaint related to dark spaces in her teeth (Figure 1). The complete periapical radiographs can be seen in Figure 2. During detailed anamnesis, full mouth periodontal probing was performed, and we found several sites showing up to $8 \mathrm{~mm}$ of probing depth and up to $10 \mathrm{~mm}$ of clinical attachment loss(bone loss that was also seen in the periapical radiographs). We requested blood exams and got in touch with her Medical Doctor to verify if she had any other conditions. We concluded she was medically healthy, presented rapid bone and attachment loss which did not correlate with the amount of plaque found, besides there was familial aggregation. The three primary features mentioned gave us a match to aggressive periodontitis diagnosis and it is in accordance with American Academy of Periodontology Classification [15]. She presented a greater depth of probing $(7 \mathrm{~mm}$ and $8 \mathrm{~mm})$ in the palatal region of the 21(Figure 3) and underwent periodontal treatment which consisted of basic scaling and root planning procedures and oral hygiene orientation in order to control the disease. However, the gingival loss of the anterior region was still large and the dark spaces persisted. To address this problem, a gingival epithesis or artificial gingiva (acrylic resin) was suggested as a complement to the treatment. Initially an alginate impression was done, then the cast was relieved with wax (Figure 4) and a custom tray was made (Figure 5). The settings of the custom tray were made so that it did not interfere with the patient's muscular insertions. Figure 6 illustrates the impression obtained with a wax dam to grant effective peripheral sealing.

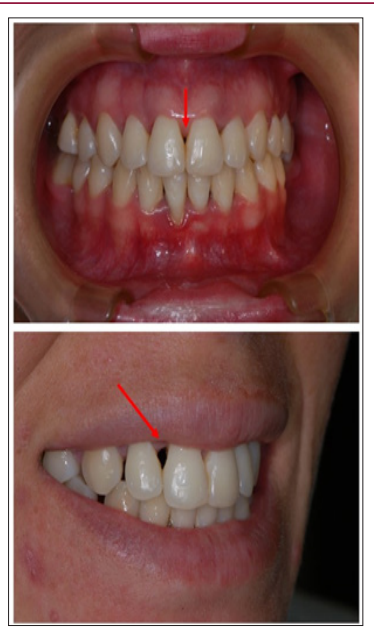

Figure 1: Frontal and lateral views of the patient on the first day of consultation (red arrows point at black triangles).
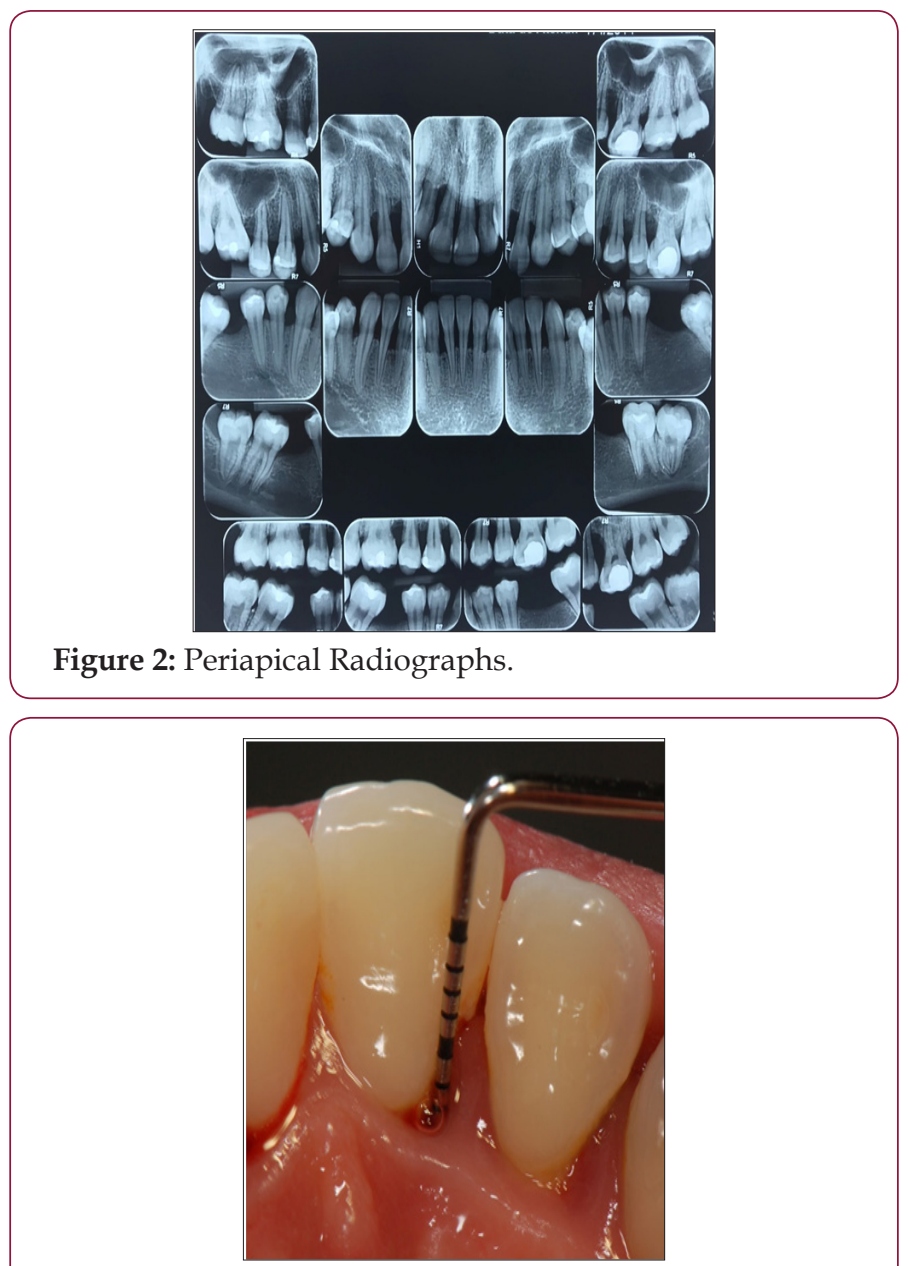

Figure 3: Probing the palatal region of 21.

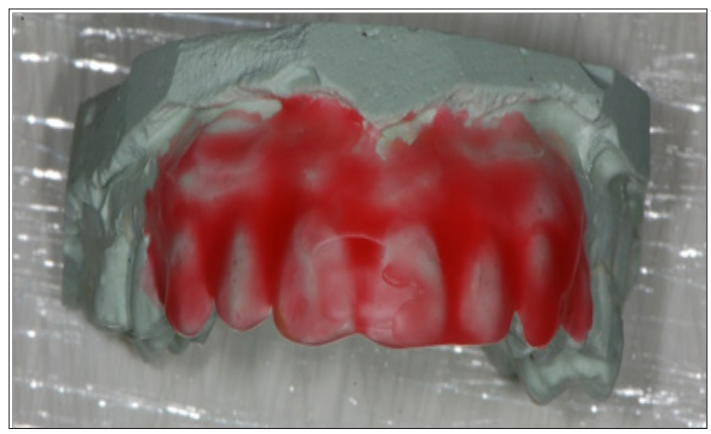

Figure 4: Working cast with Wax 07 relief.

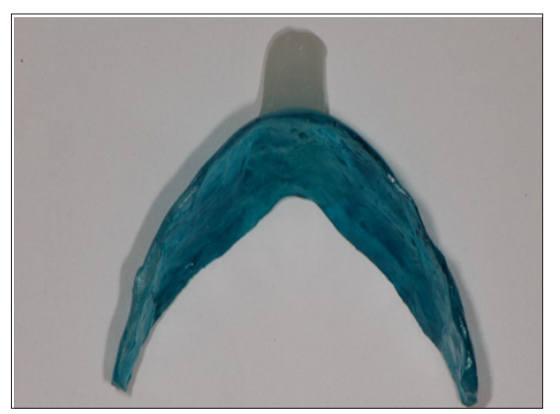

Figure 5: Custom tray with impression. 


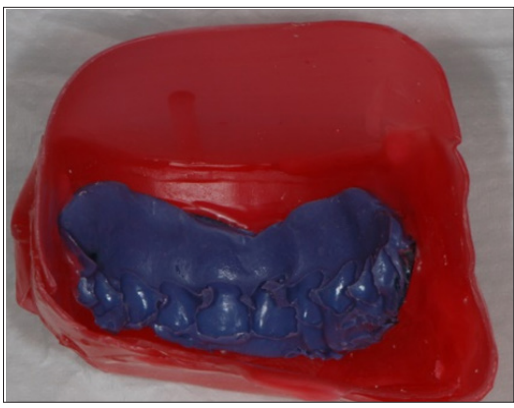

Figure 6: Impression with the dam.

The cast was then done with special type $V$ gypsum and, on top of it the artificial gingiva was waxed (Figure 7) for the wax try-in. In this phase the limits of the artificial gingiva were verified, as well as the volume of the labial support obtained (Figure 8). The labial support was slightly enlarged but did not interfere aesthetically or displeased the patient. Also, at this stage, the gingiva color was selected with the aid of a Tomáz Gomes resin characterization scale (STG). After the clinical test, the laboratorial processing of the removable gingiva was done. Figure 9 shows the immediate final result of the installation of the removable gingival epithesis, where a satisfactory aesthetic is observed. The stability is due to its intimate adaptation in the proximal niches and by the muscular force exerted by the labial musculature. The internal aspect of the artificial gingiva has extensions that fill the proximal niches, which favors the retention of the gum and prevents air leak (Figure 10). During the control phases, the patient was instructed regarding oral hygiene in a manner similar to removable prostheses. It was also noted if the artificial gingiva is compressing the periodontal tissues; in which case it was be properly adjusted. The patient returned after 7 months (Figure 11) and was satisfied with the treatment, reporting that she felt more comfortable when smiling.
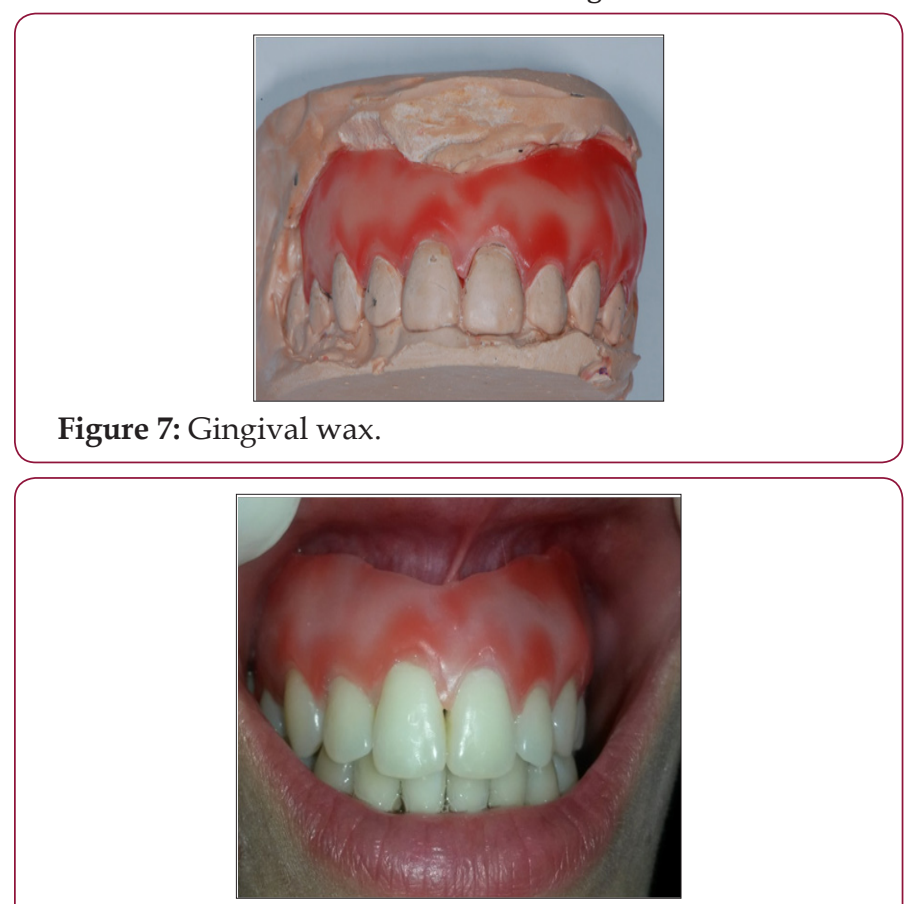

Figure 8: Gingival wax try-in.
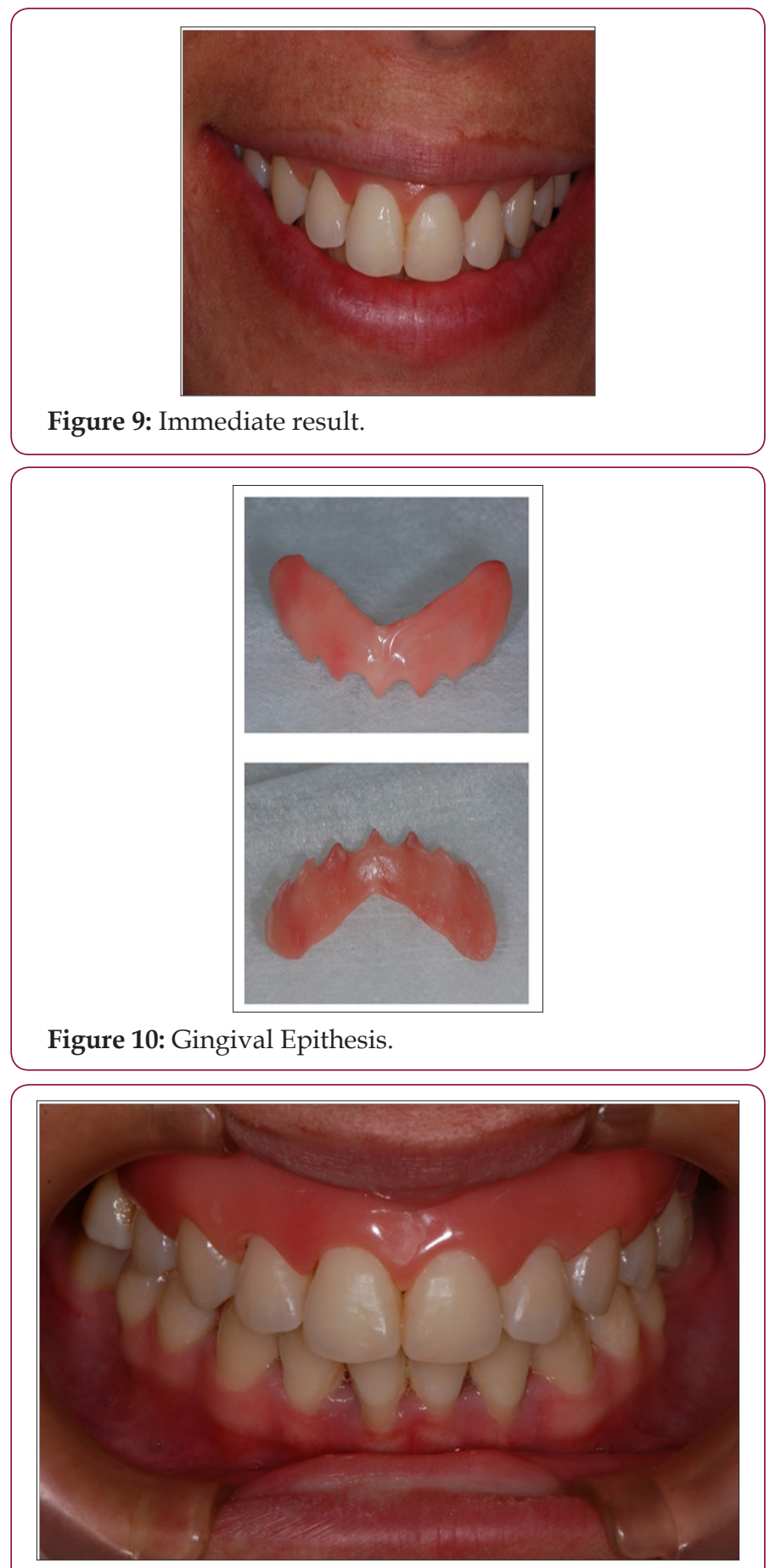

Figure 11: result of 7 months of follow-up.

\section{Discussion}

All complex treatments require prior planning and correct diagnosis, which in this disease may be very tricky $[5,16]$. Therefore, before indicating artificial removable epithesis, the patient should be evaluated for the need to recover the perimeter of the decreased arch as a result of horizontal bone resorption of the maxilla in the edentulous region [13]. In our case, the clinical attachment loss varied from 2 to $10 \mathrm{~mm}$, mostly in the upper anterior region, which left a large triangular dark space and bothered the patient aesthetically. This type of prosthesis simulates the presence of the interdental 
papilla, filling the bone loss, reestablishing aesthetics and phonetics $[4,17]$. In this sense, the artificial gingiva becomes more an aesthetic and phonetic resource within the reach of the clinician in the rehabilitations that involve great anterior bone losses. It is important to emphasize the stage of evaluation of the real periodontal condition of aesthetic surgical solutions for the case. There are situations in which there is a great limitation from the surgical point of view, but there is still a need for aesthetics, therefore in these cases prosthesis may be the best choice. Among the advantages of removable artificial gingiva in relation to surgical procedures, it can be mentioned that the prosthesis is a faster and less expensive procedure, provides a predictable and reversible aesthetic result, phonetic improvement and lip support, as well as aids in the prevention of food impaction. It is comfortable, with good adaptation and it is stable during mastication and speech. In addition, it is easy to make, install, remove and sanitize, and can be manufactured with various materials [18,19]. Costa et al. [19] summarize the removable artificial gingiva as a simple and safe solution.

The professional needs, following the basic principles of dental prosthesis, to copy well the region to be rehabilitated $[13,17]$, to properly select colors and characterizations, and to allow adjustments so that the oral epithelium is not wounded or causes rejections such as those expected in treatments using unadapted prostheses. The indications should be meticulously evaluated as well as the contraindications. The prosthesis that will be installed in a periodontally compromised patient brings benefits, but also some of its disadvantages are plaque accumulation, food remnants and pigmentation that favor the growth of fungi such as Candida albicans [18]. The benefits that this resource will bring to the patient must overcome their disadvantages so that one can consider the making of this type of prosthesis. Initially the patient must be instructed about basic oral hygiene since aggressive periodontal disease causes alveolar bone loss in an increased rate and in response to a minimum aggressor stimulus. The patient's awareness of their oral condition is very important, as they are usually a lay person and may neglect certain oral care. The patient will undergo an adaptation phase, and this should be discussed prior to treatment. Professional monitoring is fundamental, especially in relation to the possible adjustments that will be made in the prosthesis so that it is fully adapted [20]. The psychological aspect of the treatment is highly relevant: the patient will have fixed teeth, but part of their prosthesis will be removable, so during the waxing try-in, phonetic tests should be performed, and they should wear it for a few minutes in front of a mirror. It is always suggested to make more than one prosthesis because it is very delicate and the possibility of breaking or deforming is high [20].

\section{Conclusion}

The gingival epithesis is a type of prosthesis that satisfactorily reestablishes aesthetics and phonetics in patients who have lost bone height and result in a better quality of life. Patients with aggressive periodontitis present problems of rapid bone loss and consequently the appearance of "dark spaces" that generate aesthetic, phonetic and functional damage even after periodontal treatment.
There are several aspects that must be taken into account before making any type of prosthesis from the type of bone and gingival support, level of discipline and hygiene of the patient and even the psychological side should be worked out, exposing the need for maintenance of both the periodontal treatment as well as the new prosthesis installed. If these aspects are respected and well established the gingival epithesis can reach its objectives.

\section{References}

1. Lindhe J, Lang NP, Lang NP (2015) Clinical Periodontology and Implant Dentistry. ( $6^{\text {th }}$ Edn) GB: Wiley-Blackwell.

2. Müller H (2016) Periodontology: the essentials (2 ${ }^{\text {nd }}$ Edn) Norway Thieme.

3. Lang N, Bartold PM, Cullinan M, Jeffcoat M, Mombelli A, et al. (1999) Consensus Report: Aggressive Periodontitis. Ann Periodontol 4(1): 53.

4. Baumhammers A (1969) Prosthetic gingiva for restoring esthetics following periodontal surgery. Dental digest 75(2): 58-61.

5. Clark D, Levin L, Febbraio M (2017) Aggressive periodontitis: The unsolved mystery. Quintessence Int 48(2): 103-111.

6. Cronin RJ, Wardle WL (1983) Loss of anterior interdental tissue: Periodontal and prosthodontic solutions. J Prosthet Dent 50(4): 505509.

7. Beagle JR (1992) Surgical reconstruction of the interdental papilla: case report. Int J Periodontics Restorative Dent 12(2): 145-151.

8. Shah R, Thomas R, Mehta DS (2015) Recent modifications of free gingival graft: A case series. Contemp Clin Dent Jul 6(3): 425-427.

9. Han TJ, Takei HH (1996) Progress in gingival papilla reconstruction. Periodontol 11(1): 65-68.

10. Azzi R, Etienne D, Carranza F (1998) Surgical reconstruction of the interdental papilla. Int J Periodontics Restorative Dent 18(5): 466-473.

11. Azzi R, Etienne D, Sauvan JL, Miller PD (1999) Root coverage and papilla reconstruction in Class IV recession: a case report. Int J Periodontics Restorative Dent 19(5): 449-455.

12. Cortellini P (2006) Reconstructive periodontal surgery: a challenge for modern periodontology. Int Dent J 56(4 Suppl 1): 250-255.

13. Spiekermann H, Donath K, Hassel T, Jovanovic S, Richter J (1995) Color atlas of dental medicine: Implantology. ( $\left.1^{\text {st }} \mathrm{Edn}\right)$ Noway: Thieme.

14. Guerreal CMF, Moraes S, Carreiro AFP Carreiro, Amaral BA (2008) Removable gingival epithesis: esthetic and quick alternative resolution for anterior periodontal tissue replacement. RGO: Revista Gaúcha de Odontologia 56(4): 451-455.

15. Geurs N, Iacono V, Krayer J, Mealey B, Paquette D, Pearson B, et al. (2005) American Academy of Periodontology Task Force Report on the Update to the 1999 Classification of Periodontal Diseases and Conditions. J Periodontol 86(7):835-838.

16. Catunda R, Levin L, Kornerup I, Gibson MP (2018) Diagnosis of aggressive periodontitis: A dilemma? Quintessence Int 49(3): 173-180.

17. Rezende AB (1997) Acrylicresingumcaracterized. Rev Fac Odontol Univ Fed Bahia 16/17: 44-52.

18. Freitas Rd, Bonachela WC, Pedreira, Ana Paula Ribeiro do Vale, Vieira GR, et al. (2001) Aesthetic improvement in oral rehabilitation using the artificial removable gingival prosthesis: case report BC I9(32): 271-275.

19. Costa LCR, Maciel VS, Lago DM, Leal HM (1987) Fixed prosthesis with removable gum. RGO 35(6): 463-464.

20. Santos LDB, Sampaio NM, Nakamae AE (2006) Rehabilitation of the perioral musculature: removable artificial gingiva. Sitientibus (34): 115127. 
(C) (P) This work is licensed under Creative Submission Link: https://biomedres.us/submit-manuscript.php

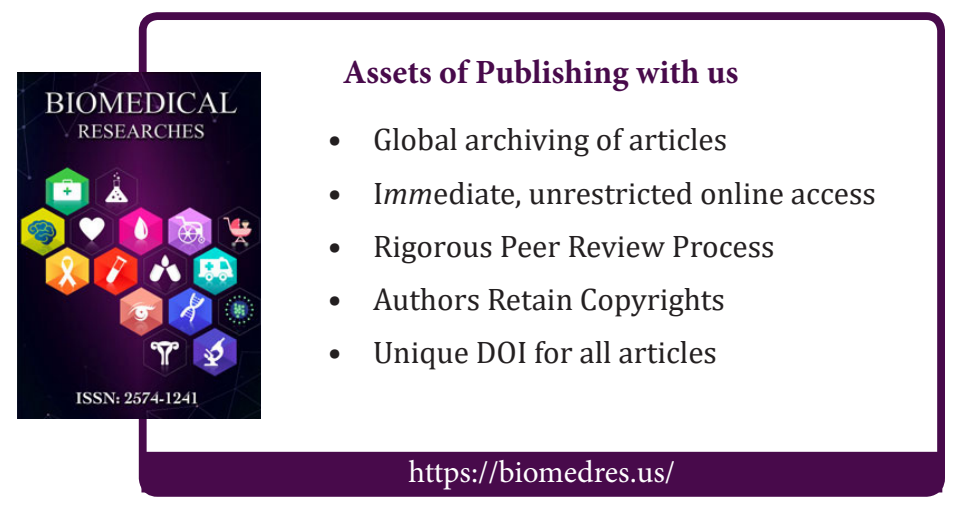

